Article

\title{
CFD Analysis of Convective Heat Transfer Coefficient on External Surfaces of Buildings
}

\author{
Andrea de Lieto Vollaro, Giorgio Galli and Andrea Vallati * \\ Department of Ingegneria Astronautica, Elettrica ed Energetica, Sapienza University of Rome, \\ Via Eudossiana 18, 00184 Rome, Italy; E-Mails: andrea.delietovollaro@uniroma1.it (A.L.V.); \\ giorgio.galli@uniroma1.it (G.G.) \\ * Author to whom correspondence should be addressed; E-Mail: andrea.vallati@uniroma1; \\ Tel.: +39-06-44585-664; Fax: +39-06-49915-905.
}

Academic Editor: Francesco Asdrubali

Received: 21 May 2015 / Accepted: 30 June 2015 / Published: 13 July 2015

\begin{abstract}
Convective heat transfer coefficients for external building surfaces are essential in building energy simulation (BES) to calculate convective heat gains and losses from building facades and roofs to the environment. These coefficients are complex functions of: building geometry, building surroundings, local air flow patterns and temperature differences. A microclimatic analysis in a typical urban configuration, has been carried out using Ansys Fluent Version 14.0, an urban street canyon, with a given H/W ratio, has been considered to simulate a three-dimensional flow field and to calculate the thermal fluid dynamics parameters that characterize the street canyon. In this paper, the convective heat transfer coefficient values on the windward external façade of the canyon and on the windward and leeward inner walls are analyzed and a comparison with values from experimental and numerical correlations is carried out.
\end{abstract}

Keywords: urban canyon; convective heat transfer coefficient; CFD; fluid dynamic; thermal field

\section{Introduction}

Thermal conditions in street canyons are important topics of urban microclimate, that influence the buildings energy demand and have a large impact on the thermal comfort and health of the people [1]. Surface temperature distribution and air circulation play an important role on heat exchanges between 
the building and canyon air, that in turn influence pedestrian comfort and the energy demand of buildings [2-9].

In this paper, the convective heat exchange between the exterior building surfaces and the external environment has been studied, because this heat exchange can be 3 to 4 times higher than long-wave radiative heat exchange [10].

Convection heat transfer between solid wall surfaces and the surrounding air plays an important role in building energy performance, indoor air temperature distribution, buoyancy-driven flow motion, etc. Knowledge of the convective heat transfer coefficients (CHTC), is required to assess the energy performance of buildings [10-12]. It is used by Building Energy Simulation programs.

Blocken et al. [12] studied the importance of using an appropriate CHTC model for simulations of a specific building. In effect the results show that the cooling energy demand is more sensitive to different convection models than the heating energy demand.

Apart from buildings, the CHTC is also used in Urban Canopy models [13-15], which are developed to assess the climate in urban areas, e.g., heat islands, that require accurate predictions of the CHTC, on the ground, or roofs or vertical walls. These mesoscale models use CHTCs to quantify the turbulent heat fluxes from building surfaces and streets in the urban canopy.

The convective heat transfer coefficient is influenced by several factors, such as the geometry of the building and building surroundings, the position at the building envelope, the building surface roughness, wind speed, wind direction, local airflow patterns and surface to air temperature differences [16].

In urban areas, local airflow patterns around a building strongly depend on the arrangement and geometry of neighboring buildings [17] which strongly influence the convective heat transfer coefficients. Terrain type influences the mean wind speed and turbulence intensity profiles [18], which also influence the CHTC [16].

There are different methods to obtain values for CHTC, which can be categorized as: analytical, wind-tunnel experiments or full-scale experiments on buildings [19,20] and the numerical method [21]. Analytical methods are only applicable for some specific flow regimes and simple geometries, e.g., flat plates and cylinders [22].

Wind-tunnel experiments of convective heat transfer at the surfaces of bluff bodies can also be used [23]. Most of these experiments however consider bluff bodies in rather thin boundary layers and at relatively low Reynolds numbers $(\operatorname{Re}=103 / 105)$ which makes them not directly applicable for atmospheric flow around buildings. Note that many of the existing correlations only consider a single CHTC value for a specific surface and do not take into account the distribution of the correlation over the surface.

Another option to obtain CHTCs is to use Computational Fluid Dynamics (CFD). The main advantages of CFD are that, for a specific building or building configuration, high spatial resolution can be obtained and high-Reynolds number flows for atmospheric conditions $(\mathrm{Re}=105 /-107)$ can be considered.

Apart from the flow field, detailed information of the thermal field is available, also in the boundary-layer region, which is valuable for the analysis of the CHTC. In building aerodynamics, steady RANS is frequently used to model air flow, compared to unsteady RANS (URANS) or Large-Eddy Simulations (LES). 
In CFD simulations, two options for modeling flow parameters in the near-wall region exist: low-Reynolds number modeling (LRNM) and wall functions method. For the first model, a very high grid resolution is required close to the wall and so very high computational cost is associated. Therefore, wall functions are commonly used instead. They are semiempirical formulae that model the region between the wall and the logarithmic layer. So that much coarser grids can be used.

In Bloken et al. [24] it is shown that in recirculating and stagnation flows and when natural convention is relevant, standard wall functions model can overpredict the CHTC values and propose modifications of the standard wall function.

In [25], it is shown that in urban canyons the SWF give CHTC that agree with LRNM, if natural convection effects are moderate, that is when the Richardson number, $\mathrm{R}_{\mathrm{i}}$, defined as $\mathrm{R}_{\mathrm{i}}=\mathrm{gH} \Delta \mathrm{T} / \mathrm{u}_{0}^{2}$ is lower than 1 , but for high values of $\mathrm{R}_{\mathrm{i}}$ modified wall function are needed.

In this paper, following the studies and validations made in $[2,3]$ we study the impact of surface heating on heat exchanges and flow fields within an isolated tridimensional canyon and on the external windward façade.

This paper is organized as follows. Section 2 describes the numerical model used in the numerical simulations. In Section 3 a comparison between convective heat transfer coefficient values on the windward and leeward façade within an urban canyon and on the windward external façade given by our simulations and the CHTC given by experimental correlation [19,20-27] and by numerical simulations by other authors [21] is carried out.

\section{CFD, Numerical Model}

The simulations have been performed with the commercial CFD code Ansys Fluent 14.0, 3D double precision, pressure based version and the steady RANS equations have been solved in combination with the standard $k-\varepsilon$ model.

The governing equations can be expressed as follows.

Momentum equation:

$$
\bar{u}_{J} \frac{\partial \bar{u}_{\imath}}{\partial x_{j}}=-\frac{1}{\rho} \frac{\partial \bar{p}}{\partial x_{i}}+\frac{\mu}{\rho} \frac{\partial^{2} \bar{u}_{\imath}}{\partial x_{i} \partial x_{j}}-\frac{\partial}{\partial x_{j}}\left(\overline{u_{\imath}^{\prime} u_{\jmath}^{\prime}}\right)+f_{i}
$$

Continuity equation:

$$
\frac{\partial \bar{u}_{l}}{\partial x_{i}}=0
$$

Heat conservation equation:

$$
\bar{u}_{\imath} \frac{\partial \bar{T}}{\partial x_{i}}+\frac{\partial}{\partial x_{i}}\left(K_{T} \frac{\partial \bar{T}}{\partial x_{i}}\right)=0
$$

where $\bar{u}_{\imath}$ is the average speed of air flow; $\overline{u_{\imath}^{\prime} u_{\jmath}^{\prime}}$ is the Reynolds stress; $\rho$ is the air density; $\mu$ is the molecular viscosity; $f_{i}$ is the thermal-induced buoyant force; $\bar{T}$ is the potential temperature; $K_{T}$ is the heat diffusivity. The standard $k-\varepsilon$ model has been used to solve the turbulence problem. The turbulence kinetic energy, $k$, and its rate of dissipation, $\varepsilon$, are obtained from the following transport equations:

$$
\frac{\partial}{\partial t}(\rho k)+\frac{\partial}{\partial x_{i}}\left(\rho k u_{i}\right)=\frac{\partial}{\partial x_{j}}\left[\left(\mu+\frac{\mu_{t}}{\sigma_{k}}\right) \frac{\partial k}{\partial x_{j}}\right]+G_{k}+G_{b}-\rho \varepsilon
$$


and

$$
\frac{\partial}{\partial t}(\rho \varepsilon)+\frac{\partial}{\partial x_{i}}\left(\rho \varepsilon u_{i}\right)=\frac{\partial}{\partial x_{j}}\left[\left(\mu+\frac{\mu_{t}}{\sigma_{\varepsilon}}\right) \frac{\partial \varepsilon}{\partial x_{j}}\right]+C_{1 \varepsilon} \frac{\varepsilon}{k}\left(G_{k}+C_{3 \varepsilon} G_{b}\right)-C_{2 \varepsilon} \rho \frac{\varepsilon^{2}}{k}
$$

where $G_{k}$ is the generation of turbulence kinetic energy due to the mean velocity gradients; $G_{b}$ is the generation of turbulence kinetic energy due to buoyancy; $C_{1 \varepsilon}, C_{2 \varepsilon}$ constants and the $K_{T}$ and $\mu_{t}$ expressions are reported in the standard $k-\varepsilon$ model of Ansys Fluent 14.0, 2011; $\sigma_{k}$ and $\sigma_{\varepsilon}$ are the turbulent Prandtl numbers for $k$ and $\varepsilon$, respectively.

The degree to which $\varepsilon$ is affected by the buoyancy is determined by the constant $C_{3 \varepsilon}$. In Ansys Fluent, $C_{3 \varepsilon}$ is not specified, but is instead calculated according to the following relation:

$$
C_{3 \varepsilon}=\tanh \left|\frac{v}{u}\right|
$$

where $v$ is the component of the flow velocity parallel to the gravitational vector and $u$ is the component of the flow velocity perpendicular to the gravitational vector. In this way, $C_{3 \varepsilon}$ will become 1 for buoyant shear layers for which the main flow direction is aligned with the direction of gravity. For buoyant shear layers that are perpendicular to the gravitational vector, $C_{3 \varepsilon}$ will become zero (Ansys Fluent Version 14.0.0, 2011). To evaluate the impact of thermal effects, the natural convection module has been activated by setting an incompressible ideal gas model for air density. The radiation exchanges have been evaluated setting up the S2S radiation model, in which the energy exchange parameters are accounted for by a geometric function called a "view factor". The simulated urban canyon has the following characteristics: it has an aspect ratio $H / W=1$ and $L / W=5$, the orientation is $\mathrm{N}-\mathrm{S}$, the building's width and height are $20 \mathrm{~m}$, the street width is $20 \mathrm{~m}$ and the street length is $100 \mathrm{~m}$. A steady state simulation has been carried out with the fixed ambient temperature, by varying the building walls and ground temperature and varying the wind speed but using only one direction $45^{\circ} \mathrm{N}$.

In $[2,3-16]$ it is shown that the average CHTC on the windward façade is not very sensitive to wind direction so that a wind direction of $45^{\circ}$ from the normal can represent a wide range of wind directions between $0^{\circ}$ and $60^{\circ}$.

Based on the best practice guidelines by Franke et al. [28] and Tominaga et al. [29], the extension of computational domain is: $23 \mathrm{H} \times 15 \mathrm{H} \times 6 \mathrm{H}$. These dimensions values have been chosen to take into account of the blockage ratio and to ensure the flow re-development behind the building region. To ensure a high quality of the computational grid, it is fully structured and the shape of the cells has been chosen as hexahedral (Figure 1). Particularly, the temperature of surfaces were fixed at a value of $30{ }^{\circ} \mathrm{C}$ higher than that of the air, the temperature of undisturbed air $(303 \mathrm{~K})$, the temperature of the internal air of the buildings $(299 \mathrm{~K})$. To simulate the ground influence, the computational domain has been extended $5 \mathrm{~m}$ below the ground level. The ground has been simulated setting the following parameters: density $=1000 \mathrm{~kg} / \mathrm{m}^{3}$; specific heat $=1000 \mathrm{~J} / \mathrm{kgK}$; thermal conductivity $=2 \mathrm{~W} / \mathrm{mK}$; temperature at $-5 \mathrm{~m}=288 \mathrm{~K}$; emissivity $=0.9$; solar radiation absorptivity (direct visible and infrared) $=0.8$ [3]. Furthermore, the materials characteristics have been reported in Bottillo et al. (2013) [3]: i.e., the building walls have: density $=1000 \mathrm{~kg} / \mathrm{m}^{3}$; specific heat $=1000 \mathrm{~J} / \mathrm{kgK}$; thermal conductivity $=0.15 \mathrm{~W} / \mathrm{mK}$; thickness $=0.30 \mathrm{~m}$; internal air temperature $=299 \mathrm{~K}$; emissivity $=0.9$; solar radiation absorptivity (direct visible and near infrared) $=0.8$. 
According to the study of Ramponi and Blocken [30], the velocity profile has been set giving a uniform velocity magnitude at the velocity inlet boundary, the turbulence intensity at $10 \%$ and the roughness length $\mathrm{z}_{0}=0.05 \mathrm{~m}$. As the flow approaches the built area, the velocity inlet profile is fully-developed before reaching the buildings $[2,3]$.

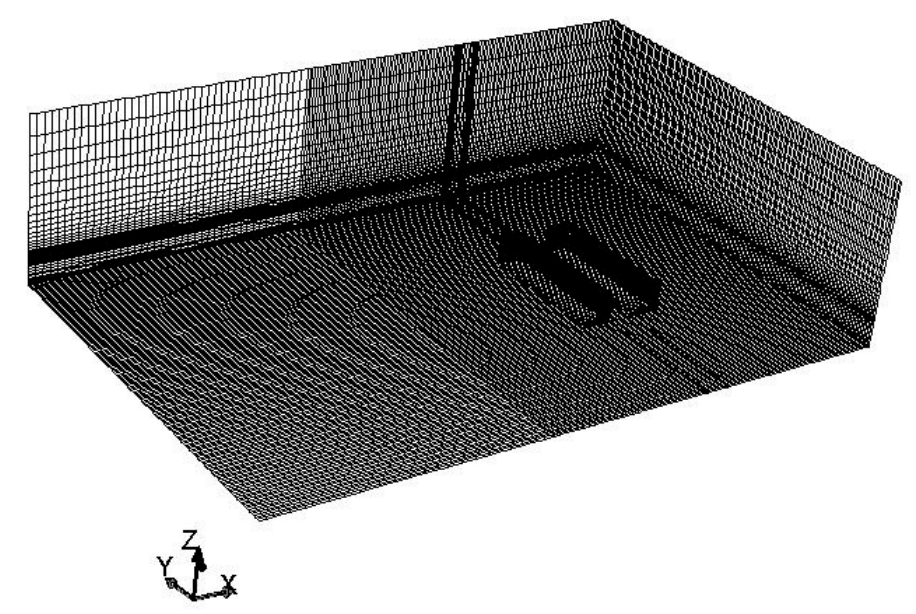

Figure 1. Domain canyon mesh.

\section{Results}

In this paper, several CFD simulations have been performed in order to evaluate the heat exchanges within an isolated tridimensional canyon that has the following geometric characteristics: aspect ratio $H / W=1$ and $L / W=5$, the width and height of buildings are $20 \mathrm{~m}$, the street width is $20 \mathrm{~m}$ and its length is $100 \mathrm{~m}$ (Figure 2).

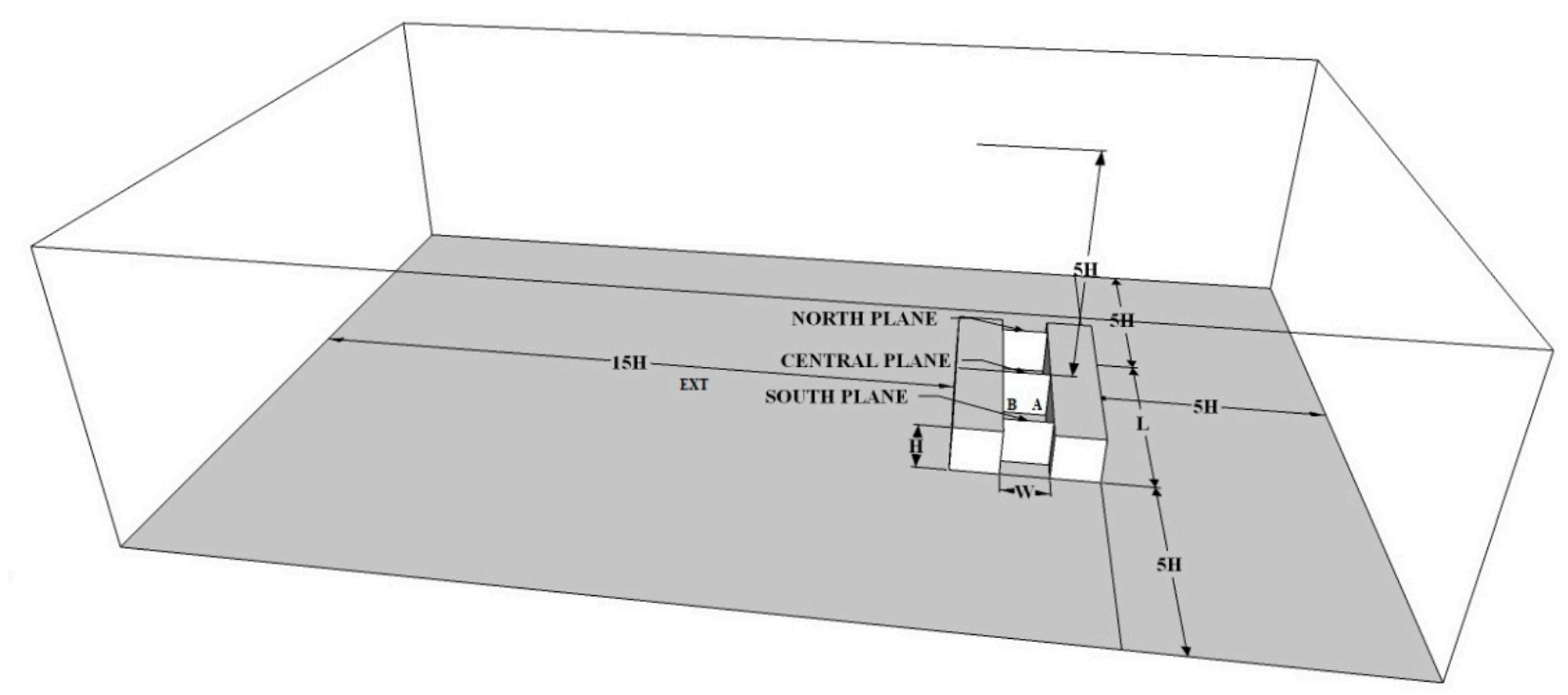

Figure 2. Computational domain.

The value of convective heat transfer coefficient for different thermal conditions of the buildings surface and the ground has been studied, both for an external façade of the canyon that for the façade inside the canyon. 
As reported in $[3,16]$, the average value of convective heat transfer coefficient on building façades within an urban canyon depends strongly on the ambient wind velocity magnitude ( $\mathrm{u}_{0}$ and less on the wind direction, even if along the canyon, the convective heat transfer coefficient can have strong variations.

In $[3,16]$ is shown that the average CHTC on the windward façade is not very sensitive to wind direction so that a wind direction of $45^{\circ}$ from the normal can represent a wide range of wind directions between $0^{\circ}$ and $60^{\circ}$.

This conclusion allows us to perform a parametric analysis on the average values of convective heat transfer coefficient, based on results of 3D CFD simulations characterized by an average wind direction. Considering an ambient wind direction of $+45^{\circ}$, several simulations have been performed on an isolated street canyon $(H / W=1)$ subject to different wind intensities and thermal fields. We have divided our canyon in three zones. The northern zone of the input air flow, a central zone and a south zone of the air flow exit. We made three lines on the first node near the windward walls and leeward representative of these three areas and we found the average value of the CHTC in all these nodes [2,3,31-33].

In order to validate the CFD numerical model, a comparison with four models (Table 1), recommended in the paper [12], of convective heat transfer coefficient calculation, implemented in a BES program (ESP-r), has been performed. It is also considered a numerical correlation (Table 1) studied by Defraeye et al. [21].

As reported in [12] there is considerable uncertainty in the prediction of convective heat transfer coefficient related to the use of convection models. The four models chosen for the comparison are based on full-scale experiments and they are developed by: Loveday and Taki [20], ASHRAE task group [26], MoWITT [27] and Liu and Harris [19]. These models can be divided in two groups: Loveday and Taki and the ASHRAE task group, that are representative of buildings with $6-8$ floor (high buildings), MoWITT and Liu and Harris, that are representative of low buildings. We chose to compare results of models on the windward façade with the values obtained with the CFD canyon model, considering the external windward façade, that is the first façade subject to the ambient wind. In Figure 3, CHTC profiles related to wind speed measured at $10 \mathrm{~m}$ above ground level in the upstream undisturbed wind flow $\left(u_{10}\right)$, are shown; in CFD simulations, $u_{10}$ corresponds to the wind velocity magnitude assigned at the inlet boundary condition $\left(u_{0}\right)$. The temperature difference between the wall and the wind flow in $30{ }^{\circ} \mathrm{C}$, it is used in CFD simulation and in the Mowitt correlation. As it can be seen, CFD simulations achieve intermediate values between the two groups of models, Instead the numerical correlation of Blocken takes values similar to those for the high buildings.

Table 1. Expressions of different correlations models used in the paper.

\begin{tabular}{ccc}
\hline MODELS & \multicolumn{2}{c}{ CORRELATIONS } \\
\hline Loveday and Taki & $h_{c}=16.15 \times\left(0.68 u_{10}-0.5\right)^{0.397}$ & - \\
\hline ASHRAE task group & $h_{c}=18.6 \times u_{l o c}^{0.605}$ & $\begin{array}{c}u_{l o c}=0.5 \text { for } u_{10}<2 \mathrm{~m} / \mathrm{s} \\
u_{l o c}=0.25 u_{10} \text { else }\end{array}$ \\
\hline MoWITT & $h_{c}=\sqrt{\left[C_{t}\left(T_{s}-T_{a}\right)^{1 / 3}\right]^{2}+\left(a u_{10}^{b}\right)^{2}}$ & $\begin{array}{c}C_{t}=0.84 \pm 0.015 \\
a=2.38 \pm 0.036 \\
b=0.89 \pm 0.09\end{array}$ \\
\hline Liu and Harris & $h_{c}=1.53 u_{10}+1.43$ & - \\
\hline Defraeye Blocken Carmeliet & $h_{c}=5.14 u_{10}^{0.82}$ & - \\
\hline
\end{tabular}




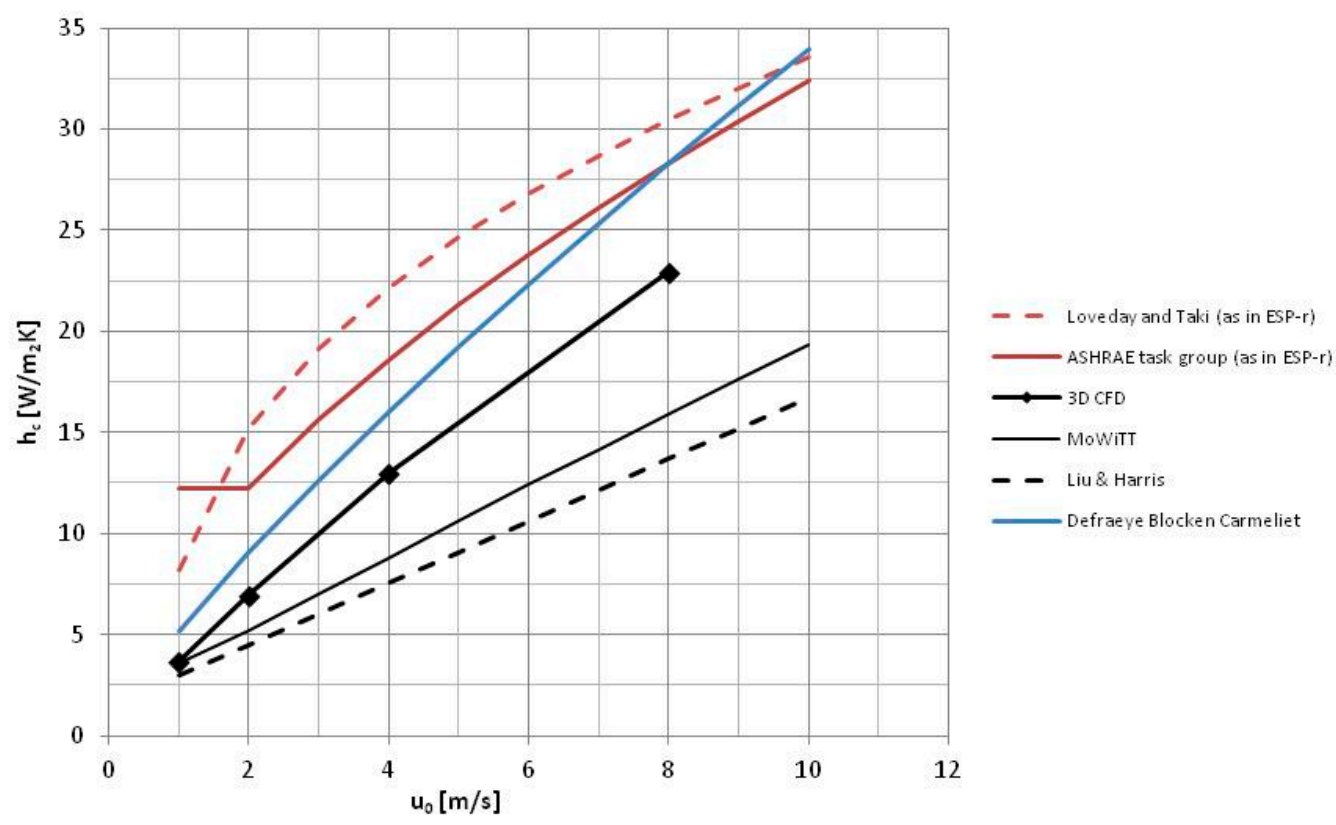

Figure 3. Comparison on convective heat transfer coefficient values calculated with correlations and 3D Computational Fluid Dynamics (CFD) simulations.

Figure 4 show the windward and leeward facades, and in Figure 5, a comparison between $h_{c}$ values on the external windward façade and the internal one is proposed.

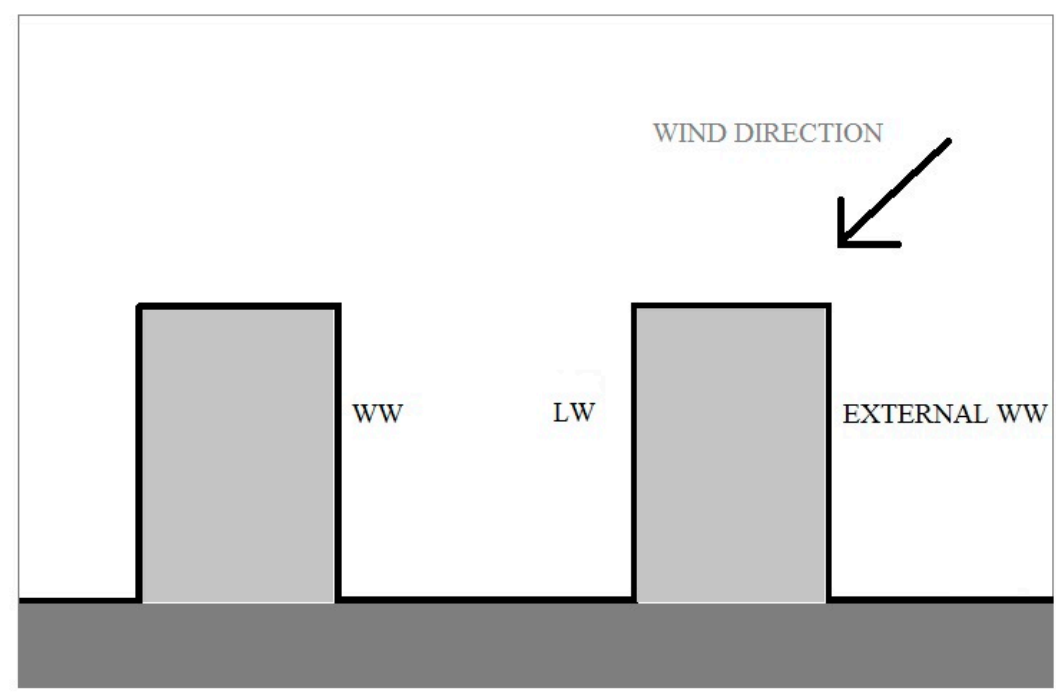

Figure 4. Windward and leeward scheme for our simulations.

The convective heat transfer coefficient on the windward façade within the canyon is always higher than the one on the external windward and, as it can be seen, by increasing the ambient wind speed, the difference increases to a value of $10 \%$. Due to natural convection effects, at low ambient wind speed, the internal windward CHTC doubles the external value.

The CFD values of convective heat transfer coefficient for an internal façade were compared to the results of a two-dimensional canyon by Allegrini et al. [34]. The parameters used for this comparison are: $H / W=1$ and the difference temperature between the surfaces is $30^{\circ} \mathrm{C}$ with convection on and off. 
Figures 5 and 6 show that the values of the convective heat transfer coefficient for our simulations are always higher than those of results of paper [34], and this should be due to the effects of the three-dimensional canyon.

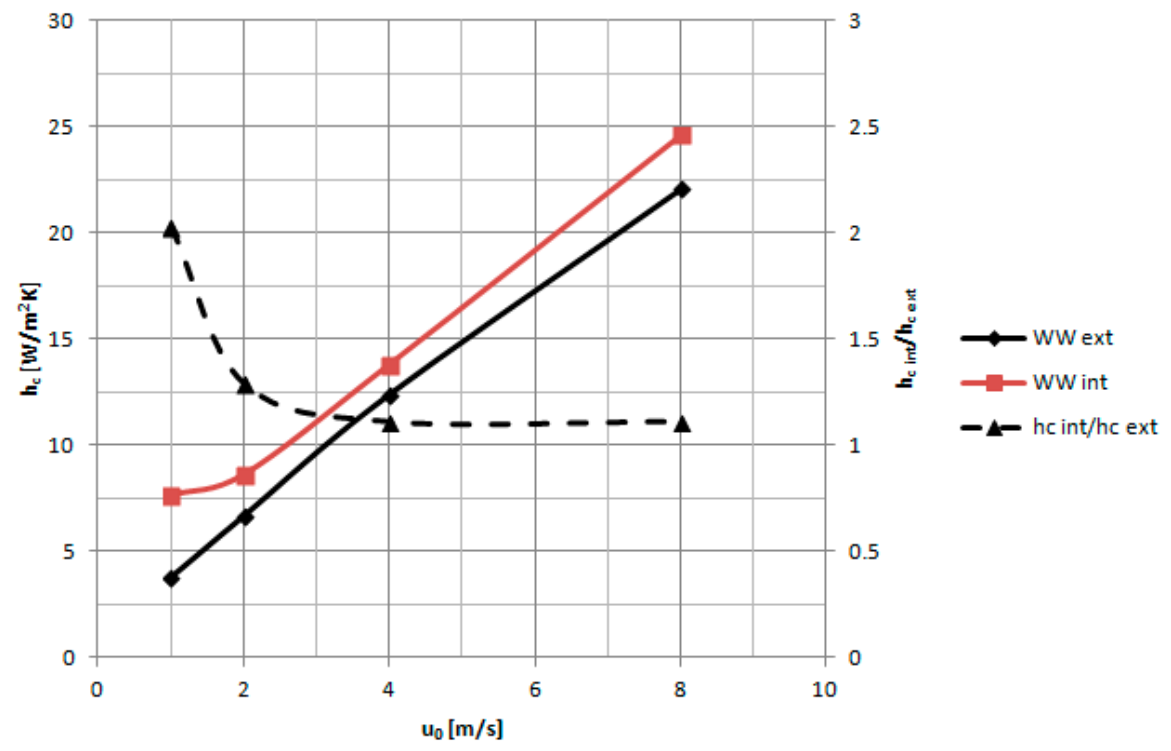

Figure 5. Comparison on convective heat transfer coefficient values (CHTC) between external and internal windward façades.

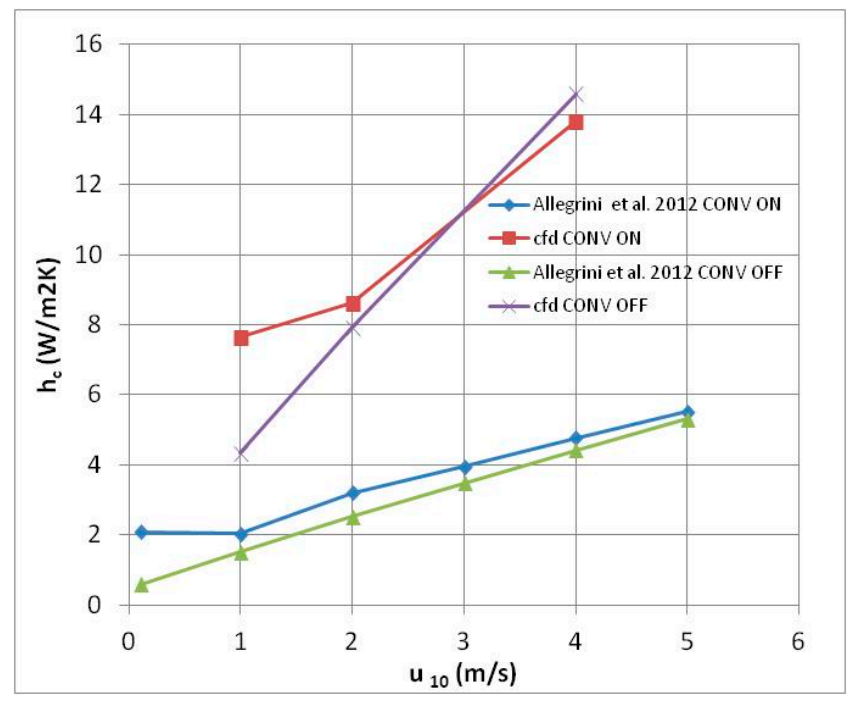

(a)

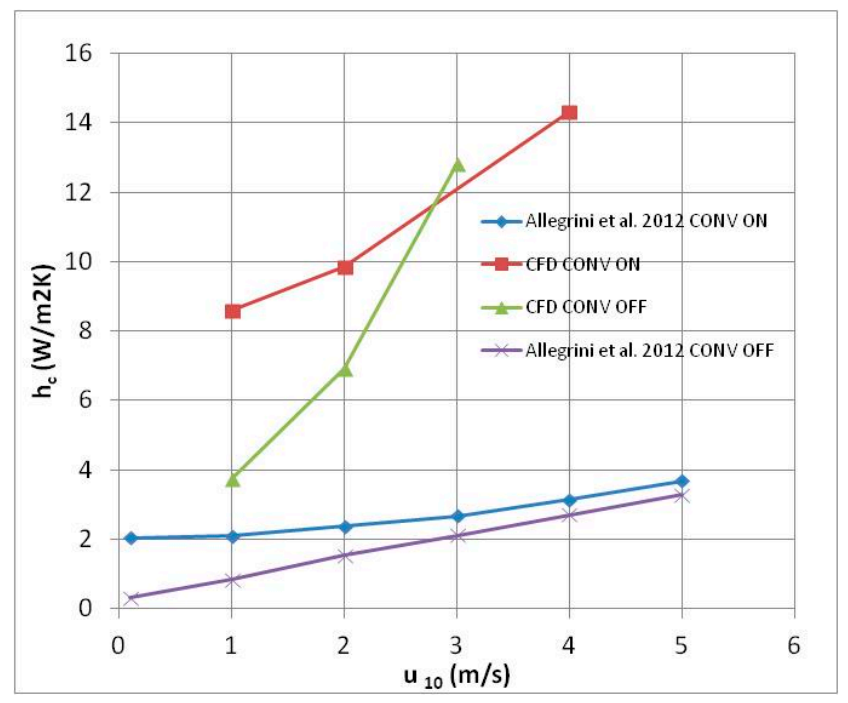

(b)

Figure 6. (a) Convective heat transfer coefficients (CHTC) versus wind speed with a temperature of $30{ }^{\circ} \mathrm{C}$ for the heated surfaces in windward facades; (b) CHTC versus wind speed with a temperature of $30{ }^{\circ} \mathrm{C}$ for the heated surfaces in leeward facades.

Three-dimensional effects produce changes in the structure and intensity of the flow field along the canyon. This could be the reason why the values of the average velocity are always higher than in the 2D simulations by Saneinejad et al. [35]. 
Bottillo et al. [2,3] showed that for each ambient wind condition the vortex structure changes significantly along the entire length of the canyon; even if the ambient wind direction is almost transversal to the canyon, there is always a remarkable longitudinal velocity component, which in turn affects the heat transfer coefficient values.

\section{Conclusions}

In this paper there is an agreement between our results and those obtained from the correlations used in BES programs, resulting from experimental data for external facades. This gives us confidence in the use within the canyon.

Furthermore, the results clearly show the coherence of using the CFD model for the evaluation of the convective heat transfer coefficient both an interior and an exterior canyon facades even if there are flows recirculating and presence of natural convection.

Differences were found between our values of hc and those obtained from other numerical work by Blocken et al. both in the canyon and exterior facades. The biggest differences are in the values within the canyon.

The difference between our values and the ones obtained by Allegrini et al. [34] seems largely due to the effect of three-dimensional CFD simulation. Furthermore, the values of $h_{c}$, reported in this paper are higher than the ones calculated in 2D models [35].

The three-dimensional effects in a canyon are very important because they change the structure of the flow field and the velocity magnitude values.

Bottillo et al. [2,3] showed that for each ambient wind condition, the vortex structure changes significantly along the entire length of the canyon; even if the ambient wind direction is almost transversal to the canyon, there is always a remarkable longitudinal velocity component, that in turn affects the heat transfer coefficient values.

Therefore, the velocity values are much higher than the values of Saneinejad et al. [35]. Since our velocity values are higher, the thermal exchange and the heat exchange coefficient increase.

The CFD results for external façades of the canyon are in good agreement with the experimental correlations. This allows us to affirm that the numerical simulation could be used to evaluate the thermal field of buildings, even when the thermal and fluid dynamic fields become a very complex problem for the presence of recirculation effects and natural convection. As regards the values in the canyon there are differences, especially if the models used are two- instead of three-dimensional. It is necessary to validate the results through experimental measurements.

\section{Author Contributions}

The authors contributed equally to this work.

\section{Conflicts of Interest}

The authors declare no conflict of interest. 


\section{Nomenclature}

CHTC: convective heat transfer coefficient $\left(\mathrm{W} / \mathrm{m}^{2} \mathrm{~K}\right)$;

$\mathrm{R}_{\mathrm{i}:}$ Richardson number;

$\mathrm{H}$ : buildings height (m);

$\mathrm{W}$ : canyon width $(\mathrm{m})$;

$\mathrm{L}$ : canyon length $(\mathrm{m})$;

$\mathbf{z}_{\mathbf{0}}$ : aerodynamic roughness length $(\mathrm{m})$;

$\mathrm{u}_{\mathrm{o}}$ : wind velocity $(\mathrm{m} / \mathrm{s})$;

WW: windward;

LW: leeward;

$\boldsymbol{\rho}$ : air density $\left(\mathrm{kg} / \mathrm{m}^{3}\right)$.

\section{References}

1. Moonen, P.; Defraeye, T.; Dorer, V.; Blocken, B.; Carmeliet, J. Urban physics effect of the micro-climate on comfort, health and energy demand. Front. Archit. Res. 2012, 1, 197-228.

2. Bottillo, S.; de Lieto Vollaro, A.; Galli, G.; Vallati, A. CFD modeling of the impact of solar radiation in a tridimensional urban canyon at different wind conditions. Solar Energy 2014, 102, 212-222.

3. Bottillo, S.; de Lieto Vollaro, A.; Galli, G.; Vallati, A. Fluid dynamic and heat transfer parameters in an urban canyon. Solar Energy 2014, 99, 1-10.

4. Baldinelli, G.F.; Asdrubali, C.; Baldassarri, F.; Bianchi, F.; D’Alessandro, S.; Schiavoni, C.B. Energy and environmental performance optimization of windows: A holistic approach. Energy Build. 2014, 79, 114-131.

5. Coppi, M.; Quintino, A.; Salata, F. Numerical study of a vertical channel heated from below to enhance natural ventilation in a residential building International. J. Vent. 2013, 12, 41-49.

6. De Lieto Vollaro, R.; Calvesi, M.; Battista, G.L.; Evangelisti, F.B. Calculation model for optimization design of the low impact energy systems for buildings. Energy Procedia 2014, 48, 1459-1467.

7. Galli, G.; Vallati, A.; Recchiuti, C.; de Lieto Vollaro, R.; Botta, F. Passive cooling design options to improve thermal comfort in an Urban District of Rome, under hot summer conditions. Int. J. Eng. Technol. 2013, 54, 4495-4500.

8. De Lieto Vollaro, R.; Vallati, A.; Bottillo, S. Different methods to estimate the mean radiant temperature in an Urban Canyon. Adv. Mater. Res. 2013, 650, 647-651.

9. De Lieto Vollaro, A.; De Simone, G.; Romagnoli, R.; Vallati, A.; Botillo, S. Numerical study of urban canyon microclimate related to geometrical parameters. Sustainability 2014, 6, 7894-7905.

10. Palyvos, J.A. A survey of wind convection coefficient correlations for building envelope energy systems modeling. Appl. Therm. Eng. 2008, 28, 801-808.

11. Clear, R.D.; Gartland, L.; Winkelmann, F.C. An empirical correlation for the outside convective air-film coefficient for horizontal roofs. Energy Build. 2003, 35,797-811. 
12. Mirsadeghi, M.; Costola, D.; Blocken, B.; Hensen, J.L.M. Review of external convective heat transfer coefficient models in building energy simulation programs: Implementation and uncertainty. Appl. Therm. Eng. 2013, 56, 134-151.

13. Masson, V. A physically-based scheme for the urban energy budget in atmospheric models. Bound. Layer Meteorol. 2000, 94, 357-397.

14. Kusaka, H.; Kondo, H.; Kikegawa, Y.; Kimura, F. A simple single-layer urban canopy model for atmospheric models: Comparison with multi-layer and slab models. Bound.-Layer Meteorol. 2001, 101, 329-358.

15. Kondo, H.; Genchi, Y.; Kikegawa, Y.; Ohashi, Y.; Yoshikado, H.; Komiyama, H. Development of a multi-layer urban canopy model for the analysis of energy consumption in a big city: Structure of the urban canopy model and its basic performance. Bound.-Layer Meteorol. 2005, 116, 395-421.

16. Blocken, B.; Defraeye, T.; Derome, D.; Carmeliet. J. High- resolution CFD simulations for forced convective heat transfer coefficients at the façade of a low rise building. Build. Environ. 2009, 44, 2396-2412.

17. Blocken, B.; Stathopoulos, T.; Carmeliet, J.; Hensen, J.L.M. Application of computational fluid dynamics in building performance simulation for the outdoor environment: An overview. J. Build. Perform. Simul. 2011, 4, 157-184.

18. Blocken, B.; Stathopoulos, T.; Carmeliet. J. CFD simulation of the atmospheric boundary layer: Wall function problems. Atmos. Environ. 2007, 41, 238-252.

19. Liu, Y.; Harris, D.J. Full-scale measurements of convective coefficient on external surface of a low-rise building in sheltered conditions. Build. Environ. 2007, 42, 2718-2736.

20. Loveday, D.L.; Taki, A.H. Convective heat transfer coefficients at a plane surface on a full-scale building façade. Int. J. Heat Mass Transf. 1996, 39, 1729-1742.

21. Defraeye, T.; Blocken, B.; Carmeliet, J. CFD Analysis of convective heat transfer at the surface of a cube immersed in a turbulent boundary layer. Int. J. of Heat and Mass Transf. 2010, 53, 297-308.

22. Cai, R.; Zhang, N. Explicit analytical solutions of 2-D laminar convection. Int. J. Heat Mass Transf. 2003, 46, 931-934.

23. Nakamura, H.; Igarashi, T.; Tsutsui, T. Local heat transfer around a wall mounted cube in the turbulent boundary layer. Int. J. Heat and Mass Transf. 2001, 44, 3385-3395.

24. Defraye, T.; Blocken, B.; Carmeliet, J. An adjusted temperature wall function for turbulent forced convective heat transfer for bluff bodies in the atmospheric boundary layer. Build. Environ. 2011, 46, 2130-2141.

25. Allegrini, J.; Dorer, V.; Defraye, T.; Carmeliet J. And adaptive temperature wall function for mixed convective flows at exterior surfaces of buildings in street canyons. Build. Environ. 2012, 49, 55-66.

26. Ito, N.; Kimura, K.; Oka, J. A field experiment study on the convective heat transfer coefficient on the exterior surface of a building. Ashrae Trans. 1972, 78, 184-191.

27. Yazdanian, M.; Klems, J.H. Measurements of the exterior convective film coefficient for windows in low rise buildings. Ashrae Trans. 1994, 100, 1087-1096.

28. Franke, J.; Hellsten, A.; Schlunzen, H.; Carissimo, B. Best Practice Guideline for the CFD Simulation of Flows in the Urban Environment. Available online: http://ir.nmu.org.ua/bitstream/ handle/123456789/129263/2fc533fe43165311a460c66f04fd4514.pdf?sequence=1 (assessed on 1 July 2015). 
29. Tominaga, Y.; Mochidab, A.; Yoshiec, R.; Kataokad, H.; Nozue, T.; Yoshikawaf, M.; Shirasawac, T. AIJ Guideline for practical applications of CFD to pedestrian wind environment around buildings. J. Wind Eng. Ing. Aerodyn. 2008, 96, 1749-1761.

30. Ramponi, R.; Blocken, B. CFD simulations of cross ventilation for a generic isolated building: impact of computational parameters. Build. Environ. 2012, 53, 34-48.

31. Łopata, S.; Ocłon, P. Numerical study of the effect of fouling on local heat transfer conditions in a high-temperature fin-and-tube heat exchanger. Energy 2015, doi:10.1016/j.energy.2015.03.048.

32. Taler, D.; Ocłoń, P. Thermal contact resistance in plate fin-and-tube heat exchangers, determined by experimental data and CFD simulations. Int. J. Therm. Sci. 2014, 84, 309-322.

33. Taler, D.; Ocłoń, P. Determination of heat transfer formulas for gas flow in fin-and-tube heat exchanger with oval tubes using CFD simulations. Chem. Eng. Process. Process Intensif. 2014, $83,1-11$.

34. Allegrini J.; Dorer V.; Carmeliet J. Analysis of convective heat transfer at building facades in street canyons and its influence on the predictions of space cooling demand in buildings. J. Wind Eng. Ind. Aerodyn. 2012, 104-106, 464-473.

35. Saneinejad, S.; Meonen, P.; Defraeje, T.; Carmeliet, J. Analysis of convective heat and mass transfer at the vertical walls of a street canyon. J. Wind Eng. Ind. Aerodyn. 2011, 99, 424-433.

(C) 2015 by the authors; licensee MDPI, Basel, Switzerland. This article is an open access article distributed under the terms and conditions of the Creative Commons Attribution license (http://creativecommons.org/licenses/by/4.0/). 